\title{
KAJIAN PERESEPAN ANTIBIOTIKA PADA PASIEN \\ DEWASA DI SALAH SATU PUSKESMAS KOTA \\ YOGYAKARTA PERIODE JANUARI - APRIL 2010
}

\section{ANTIBIOTIC UTILIZATION OF ADULT PATIENTS IN ONE OF THE PUBLIC HEALTH CENTER OF YOGYAKARTA CITY PERIOD JANUARY APRIL 2010}

\author{
Muhammad Muhlis \\ Fakultas Farmasi Universitas Ahmad Dahlan \\ muhlis3@yahoo.co.id
}

\section{Abstrak}

Untuk mencapai keberhasilan terapi penggunaan antibiotika salah satu faktor penunjangnya adalah ketepan dalam peresepan antibiotika itu sendiri, kesalahan dalam peresepan dapat menyebabkan ketidak rasionalan dalam penggunaan antibiotika. Ketidakrasionalan dalam peresepan antibiotika kemungkinan terjadi tidak hanya di puskesmas ataupun di dokter praktek swasta, namun juga di pusat-pusat pelayanan kesehatan lain seperti poliklinik dan rumah sakit. Penelitian ini dilakukan untuk mengkaji pola peresepan antibiotika dan tingkat kerasionalan penggunaan antibiotika pada pasien dewasa di salah satu Puskesmas Kota Yogyakarta berdasarkan data peresepan obat. Penelitian ini dirancang secara deskriptif dengan data retrospektif. Pengumpulan data dilakukan selama 4 bulan yaitu bulan Januari sampai dengan bulan April 2010. Sumber data adalah resep antibiotika pada pasien dewasa. Peresepan di kaji berdasarkan pemilihan antibiotika, tepat dosis, tepat frekuensi dan tepat durasi penggunaan antibiotika. Hasil penelitian didapat sebanyak 320 pasien mendapatkan antibiotika, dengan 6 jenis antibiotika yang digunakan yaitu amoksisilin $64,5 \%$, ampisilin $11,3 \%$, kontrimoksazol 15,9\%, kloramfenikol, 0,6\%, metronidazol 2,8\% dan tetrasiklin 4,9\%. Pasien mendapat antibiotika tunggal sebanyak 97,9\% dan pasien mendapat kombinasi antibiotika sebanyak 2,1\%.. Semua peresepan memenuhi ketepatan dosis dan frekuensi, kecuali kotrimoksasol tepat dosis $98 \%$ dan Ampisilin tepat dosis $49 \%$. Semua peresepan (100\%) tidak memenuhi ketepatan durasi penggunaan antibiotika. Secara umum karasionalan peresepan antibiotika untuk 
pasien dewasa di salah satu Puskesmas Kota Yogyakarta adalah sudah baik sesuai dengan standar penggunaan antibiotika di puskesmas, hanya perlu kajian lebih mendalam dalam hal durasi penggunaan antibiotika, sehingga dapat dibuat kebijakan baru untuk mendapatkan hasil terapi yang lebih baik

Kata Kunci : Antibiotika, Puskesmas, Kota Yogyakarta

\section{Abstract}

To achieve optimal therapy of antibiotics isonefactor supporting the accuracy in prescribing antibiotics errors in prescribing can cause lack of rationality in the use of antibiotics. Antibiotic was commonly used in the clinicor in private practice doctors but also in the centers of other health services such as polyclinics and hospitals the aim of this study is to assess antibiotic prescribing patterns and the level of rationality the use of antibiotics in adult patients at one center of Yogyakarta on the basis of data prescriptions. This Study used descriptive design with retrospective data collection The data was collected from January to April 2010 Data source is a prescription of antibiotics in adult patients We analyzed the antibiotics prescription in the study based on the selection appropriate dos age frequency and duration. We recruited 320 patients receive ing antibiotics. The of antibiotics used were amoxicillin $64.5 \%$ ampicillin $11.3 \%$ kontrimoksazol $15.9 \%$ chloramphenicol $0.6 \%$ metronidazole $2.8 \%$ and etracycline $49 \%$ Most of the Patients received a single antibiotic 97.9\%), while the remaining patients received a combination of antibiotics $2.1 \%$ All prescribing meet appropriate dosage, and frequency except cotrimoxazole (98\%) and ampicillin 49\%). All prescriptions (100\%) improper duration. In general antibiotics prescription for adult patients at one health center in Yogyakarta City is comply with the standard use of antibiotics in Public Health Centers. However, the duration of antibiotic utilization still became the perspective of the health providers in Public Health Centers.

Key word : Antibiotics, Public Health Center, Yogyakarta 


\section{PENDAHULUAN}

Penyakit infeksi masih merupakan masalah kesehatan utama di negaranegara berkembang seperti Indonesia. Penelitian yang dilakukan Djaja. S (2003) menunjukkan kasus kematian selama tahun 2000 besarnya 3.322 . Penyakit penyebab utama kematian terbesar adalah penyakit sirkulasi (jantung/ pembuluh darah otak) yaitu 222 per 100.000 penduduk, selanjutnya penyakit infeksi 174 dan pernapasan 85 per 100.000 penduduk. Angka kematian untuk penyakit infeksi dan pernapasan lebih tinggi di pedesaan (204 dan102) dibandingkan di perkotaan (136 dan 62).

Data dari puskesmas di Daerah Istimewa Yogyakarta menunjukkan bahwa urutan pertama penyebab kesakitan adalah infeksi akut pada saluran pernafasan atas $(20,96 \%)$, kedua penyakit sistem otot jaringan pengkat $(11,61 \%)$ dan ketiga diduduki penyakit lain dari saluran pernafasan atas $(2,29 \%)$. Data dari rumah sakit di Derah Istimewa Yogyakarta juga menunjukkan bahwa penyakit infeksi masih menduduki urutan teratas (Anonim, 1998).

Menurut Suryatenggara dkk. (1990) penanganan infeksi sebenarnya tidak terlalu sulit bila kita tahu penyebab serta obat untuk mengantisipasinya. Semenjak ditemukan penisilin ataupun obat-obat sulfa pada tahun 1930-an sampai saat ini berbagai jenis antibiotika dan kemoterapika banyak sekali ditemukan dan dikembangkan. Pengembangan obat-obat golongan ini merupakan suatu tonggak kemajuan dalam dunia pengobatan, oleh karana berbagai penyakit infeksi dapat diobati secara efektif atau pada beberapa keadaaan dapat dicegah terjadinya kecacatan (Santoso, 1990).

Ketersediaan antibiotika yang sangat banyak jumlahnya dalam klinik, ternyata juga membawa kesulitan bagi para praktisi terutama dalam melakukan pemilihan antibiotika secara tepat, aman dan efektif bagi seorang pasien. Cepatnya penemuan berbagai jenis antibiotika baru, sayangnya tidak diikuti secara sepadan oleh perkembangan prinsipprinsip/sistematika terapi antibiotika dalam klinik (Santoso, 1990), sehingga banyak sekali dijumpai ketidakrasionalan penggunaan antibiotika dalam klinik.

Ketidakrasionalan dalam pemakaian antibiotika kemungkinan terjadi tidak hanya di puskesmas atau pun praktek swasta, namun juga di pusatpusat pelayanan kesehatan lain seperti poliklinik dan rumah sakit (Mustofa, 1998). Salah satu contoh yang sering kita lihat di puskesmas untuk ISPA ringan, yang belum tentu disebabkan kuman, namun sebagian besar kasus (90\%) selalu mendapatkan antibiotika dan umumnya yang diberikan adalah tetrasiklin (Santoso, 1990).

Kota Yogyakarta merupakan kota pelajar, pelajar/mahasiswanya berasal dari seluruh profinsi di Indonesia (anoniom, 2011). Sehingga kota Yogyakarta dapat menjadi barometer pendidikan sekaligus pelayanan kesehatan di Indonesia. Umumnya pelajar/mahasiswa yang datang ke Jogja berasal dari kalangan menengah kebawah dan jika sakit maka puskesmaslah yang menjadi tujuan utama pengobatan. 


\section{METODE}

\section{A. Rancangan Penelitian}

Penelitian ini merupakan penelitian non eksperimental yang dirancang secara deskriptif bersifat retrospektif dengan cara melakukan kajian terhadap penulisan resep-resep pasien dewasa yang mengandung antibiotika selama bulan Januari sampai dengan bulan April 2010 untuk mengetahui pola penggunaan dan kerasionalan penggunaan antibiotik di salah satu Puskesmas Kota Yogyakarta.

\section{B. Populasi}

Populasi adalah seluruh resep yang masuk ke bagian Farmasi di salah satu Puskesmas KotaYogyakarta selama bulan Januari sampai dengan bulan April 2010 .

Target adalah seluruh resep yang mengandung antibiotika untuk pasien dewasa usia antara 20-60 tahun rawat jalan di salah satu Puskesmas Kota Yogyakarta selama bulan Januari sampai dengan bulan April 2010. Pemilihan usia 20 - 60 tahun di dasarkan karena pada usia tersebut adalah usia produktif.

\section{Pengumpulan Data}

Pengumpulan data dilakukan dengan cara mencatat resep yang mengandung antibiotik pada pasien rawat jalan dewasa usia antara 20-60 tahun Data yang dikumpulkan adalah nama, jenis kelamin dan usia pasien, jenis antibiotika, jumlah obat, dosis 1 x pakai, frekuensi selama satu kali dan durasi pemakaian antibiotika.

\section{Analisis Data}

Data yang diperoleh dianalisis dengan metode deskriptif, berdasarkan pola penggunaan antibiotika. Tingkat kerasionalan penggunaan antibiotika berdasarkan tepat dosis, tepat frekuensi dan tepat durasi, berdasarkan standar Buku Farmakope Indonesia, Drug Information Handbook tahun 2004, dan British National Formulatory 44

\section{HASIL DAN PEMBAHASAN}

\section{A. Distribusi Pasien}

Data resep yang dikumpulkan adalah identitas nama, umur dan jenis kelamin pasien, jenis antibiotika, jumlah, dosis, frekuensi dan lama pemberian antibiotika yang selanjutnya disusun berdasarkan tabel-tabel

Tabel I. Karakter Pasien penerima resep mengandung antibiotika

\begin{tabular}{|c|c|c|c|}
\hline & Keterangan & Jumlah & Presentase \% \\
\hline 1 & \multicolumn{3}{|l|}{ Umur (tahun) } \\
\hline & $20-30$ & 147 & $45,93 \%$ \\
\hline & $31-40$ & 126 & $39,38 \%$ \\
\hline & $41-50$ & 34 & $10,63 \%$ \\
\hline & $>51$ & 13 & $4,06 \%$ \\
\hline \multicolumn{2}{|r|}{ Total } & 320 & $100,00 \%$ \\
\hline 2 & \multicolumn{3}{|c|}{ Jenis kelamin } \\
\hline & Perempuan & 226 & $70,63 \%$ \\
\hline & Laki-laki & 94 & $29.37 \%$ \\
\hline & Total & 320 & $100,00 \%$ \\
\hline
\end{tabular}

Pada tabel I dapat di simpulkan bahwa pasien penerima resep antibiotika sebagian besar pada usia produktif yaitu pada usia 20 sampai dengan 50 tahun. 
Undang undang Kesehatan no 36 tahun 2009 menyatakan bahwa Kesehatan adalah keadaan sehat, baik secara fisik, mental, spritual maupun sosial yang memungkinkan setiap orang untuk hidup produktif secara sosial dan ekonomis. Maka jika pada usia produktif ini pasien mendapatkan antibiotika yang tidak rasional dapat menyebabkan tidak hanya meningkatnya angka kesakitan tetapi dapat juga menurunkan produktifitas pasien secara ekonomis. Berdasarkan jenis kelamin, pasien wanita yang mendapatkan antibiotika lebih banyak daripada pasien laki laki, sebagaimana data di tabel I, hal ini dapat disebabkan banyak faktor antara lain jumlah penduduk perempuan kota jogja adalah $51,3 \%$ sedangkan laki laki sebanyak 48,7 \% (anonim 2011b), jumlah pengunjung puskesmas lebih banyak wanita daripada laki laki

\section{Penggunaan Antibiotika}

Ada banyak antibiotika generik yang tersedia di puskesmas tetapi hanya ada 6 antibiotika yang diresepkan, seperti nampak pada tabel II, sebagian besar peresepan menggunakan antibiotika golongan $\beta$ laktam yaitu $75,84 \%$ yang terdiri dari Amoksisilin dan ampisilin, Berdasarkan penelitian yang telah dilakukan Hariani, (2006) terhadap isolate staphylococcus aureus dari usapan faring penderita ISPA di RSU PKU Muhammadiyah Yogyakarta terhadap antibiotika $\beta$ laktam menunjukkan bahwa $38 \%$ isolate telah mengalami resistensi terhadap antibiotika $\beta$ laktam, sampel pasien pada penelitian tersebut adalah penduduk kota Yogyakarta untuk itu perlu peninjauan ulang dalam penggunaan antibiotika di puskesmas Kota Yogyakarta

Tabel II. Tingkat Penggunaan antibiotika berdasarkan jenis antibiotika

\begin{tabular}{|c|c|c|}
\hline Jenis Antibiotika & Jumlah & Presentase \\
\hline Amoksisilin & 211 & $64,53 \%$ \\
\hline Ampisilin & 37 & $11,31 \%$ \\
\hline Kotrimoksazol & 52 & $15,90 \%$ \\
\hline Kloramfenikol & 2 & $0,61 \%$ \\
\hline Metronidazol & 9 & $2,75 \%$ \\
\hline Tetrasiklin & 16 & $4,89 \%$ \\
\hline Jumlah & 327 & $100 \%$ \\
\hline
\end{tabular}

Penggunaan antibiotika kombinasi dalam terapi adalah tidak dilarang selama tujuan kombinasi tersebut dalam rangka untuk meningkatkan potensi antibiotika, mencegah munculnya resistensi atau untuk terapi infeksi campuran, namun kombinasi antibiotika tidak boleh dilakukan pada 2 antibiotika satu golongan atau antibiotika yang mekanisme aksinya sama. Pada tabel III di lihat terdapat 7 peresepan kombinasi, kedua kombinasi tersebut bukan dari golongan antibiotika yang sama, tetrasiklin dan amoksisilin biasanya digunakan pada infeksi aerob, dan metronidazol biasanya digunakan pada infeksi an-aerob. Kombinasi antibiotika an-aerob aerob biasanya digunakan pada kasus infeksi tukak lambung dan infeksi gangrene pada penderita diabetes. 
Tabel III. Penggunaan Antibiotika Kombinasi

\begin{tabular}{|c|c|c|}
\hline No & Kombinasi antibiotika & $\begin{array}{c}\text { Jumlah } \\
\text { Resep }\end{array}$ \\
\hline 1 & $\begin{array}{l}\text { Tetrasiklin - } \\
\text { metronidazol }\end{array}$ & 1 \\
\hline 2 & $\begin{array}{l}\text { Amoksisilin - } \\
\text { metronidazol }\end{array}$ & 6 \\
\hline & jumlah & 7 \\
\hline
\end{tabular}

Ketepatan penggunaan antibiotika pada penelitian ini cukup baik. Dari pemilihan dosis sebagian besar antibiotika yang diresepkan sesuai dengan dosis dewasa yang direkomendasikan buku standar, hanya pada kotrimoksasol ada satu peresepan yang dosisnya kurang dapat dilihat di tabel $\mathrm{V}$, tertulis di resep 2 $\mathrm{x}$ sehari 1 tablet $(480 \mathrm{mg})$.

Tabel IV Standar Dosis Penggunaan antibiotika

\begin{tabular}{|c|l|}
\hline Antibiotika & \multicolumn{1}{|c|}{ Dosis dewasa } \\
\hline Amoksisilin & $\begin{array}{l}\text { 250-500 mg setiap 8 } \\
\text { jam }\end{array}$ \\
\hline Ampisilin & $\begin{array}{l}\text { 250-500 mg setiap 6 } \\
\text { jam }\end{array}$ \\
\hline
\end{tabular}

\begin{tabular}{|c|c|}
\hline Kotrimoksazol & 960 mg etiap 12 jam \\
\hline Kloramfenikol & $\begin{array}{l}50-100 \mathrm{mg} / \mathrm{kg} / \mathrm{hari} \text { tiap } \\
6 \text { jam } \\
(250-500 \mathrm{mg} \text { setiap } 6 \\
\text { jam })\end{array}$ \\
\hline Metronidazol & $\begin{array}{l}250 \text { - } 500 \mathrm{mg} \text { tiap } 6-8 \\
\text { jam }\end{array}$ \\
\hline Tetrasiklin & $\begin{array}{l}250-500 \mathrm{mg} \text { tiap } 6 \\
\text { jam }\end{array}$ \\
\hline
\end{tabular}

Berdasarkan standar yang ada penggunaan kotrimoksasol untuk pasien dewasa adalah $2 \mathrm{x}$ sehari 2 tablet $480 \mathrm{mg}$ (2 x sehari $960 \mathrm{mg}$ ), peresepan yang underdose ini dapat menyebabkan tidak sembuhnya pasien atau sembuh dalam jangka waktu yang lama, bahaya yang cukup besar adalah peningkatan resistensi bakteri terhadap antibakteri tersebut.

Frekuensi penggunaan antibiotika berpengaruh terhadap pencapaian kadar terapi obat dalam darah, kurangnya frekuensi penggunaan obat dapat menyebabkan kadar obat dalam darah tidak dapat mencapai kadar rentang terapi, pada akhir nya obat menjadi tidak berkhasiat. Pada tabel IV dapat dilihat

Tabel V. Ketepatan Penggunaan Antibiotika

\begin{tabular}{|l|c|c|c|c|c|c|}
\hline \multirow{2}{*}{ Jenis Antibiotika } & \multicolumn{6}{|c|}{ Ketepatan penggunaan antibiotika } \\
\cline { 2 - 7 } & \multicolumn{2}{|c|}{ Tepat dosis } & Tepat Frekuensi & \multicolumn{2}{c|}{ Tepat durasi } \\
\cline { 2 - 7 } & $\Sigma$ & $\mathbf{\%}$ & $\Sigma$ & $\mathbf{\%}$ & $\Sigma$ & $\%$ \\
\hline Amoksisilin & 0 & 100 & 0 & 0 & 0 & 0 \\
\hline Ampisilin & 0 & 100 & 18 & 49 & 0 & 0 \\
\hline Kotrimoksazol & 52 & 98 & 0 & 0 & 0 & 0 \\
\hline Kloramfenikol & 0 & 100 & 0 & 0 & 0 & 0 \\
\hline Metronidazol & 0 & 100 & 0 & 0 & 0 & 0 \\
\hline Tetrasiklin & 0 & 100 & 0 & 0 & 0 & 0 \\
\hline \multicolumn{1}{|c|}{ Total } & $\mathbf{1}$ & & $\mathbf{1 9}$ & & $\mathbf{0}$ & \\
\hline
\end{tabular}


Ampisilin sebanyak $49 \%$ tepat dalam frekuensi penggunaan obat, berarti $51 \%$ belum tepat dalam frekuensi penggunaan, untuk itu perlu sosialisasi lebih jauh terhadap para praktisi kesehatan dalam hal frekuensi penggunaan antibiotika.

Ketepatan durasi penggunaan antibiotika berdasarkan data pada tabel IV diketahui bahwa seluruh peresepan antibiotika di berikan untuk durasi pengobatan selama 3 hari. Durasi penggunaan antibiotika tergantung dari masing-masing diagnose, $B N F \quad 46$ membatasi penggunaan antibiotika minimal 5 hari untuk penyakit penyakit yang ringan, guide antibiotics menyarankan penggunaan antibiotika selama $5-7$ hari, sedang pendapat yang lain menyarankan penggunaan antibiotika adalah sampai dua hari setelah simtom hilang (anonim. 2011c)

Di puskesmas kebijakan penggunaan antibiotika (protab penggunaan antibiotika) masih selama 3 hari, jika di tinjau secara biofarmasetika untuk tujuan terapetik diperlukan lebih dari 95\% kadar tunak obat dalam darah dan ini dicapai dalam waktu enam kali waktu paruh eliminasi (Shargel, 1988). Jika obat di gunakan 3 kali sehari, untuk 6 kali waktu paruh eliminasi berarti 2 hari penggunaan, dan hanya tersisa 1 hari obat berada di kadar rentang terapi, rentang ini tidak memungkinkan untuk efektifitas antibakteri, sehingga jika di lihat kebijakan penggunaan antibiotika selama 3 hari itu diasumsikan kadar antibiotika dalam darah berada dalam jendela terapi selama 3 hari, dan waktu yang diperlukan untuk mencapai kadar pada jendela terapi adalah 2 hari, maka pemakaian yg tepan antibiotika adalah minimal 5 hari.

\section{KESIMPULAN}

Berdasarkan hasil penelitian terhadap penggunaan antibiotika pasien dewasa di salah satu puskesmas Kota Yogyakarta periode Januari sampai dengan April 2010 dapat diambil kesimpulan sebagai berikut : tercatat sebanyak 320 pasien yang mendapatkan antibiotika, dengan 6 jenis antibiotika yaitu amoksisilin 64,53\%, ampisilin $11,31 \%$, kontrimoksazol $15,90 \%$, kloramfenikol, $0,61 \%$, metronidazol $2,75 \%$ dan tetrasiklin $4,89 \%$. Sebanyak 313 pasien mendapat antibiotika tunggal dan 7 pasien mendapat kombinasi antibiotika, semua peresepan memenuhi ketepatan dosis dan frekuensi, kecuali kotrimoksasol tepat dosis $98 \%$ dan Ampisilin tepat dosis $49 \%$. Semua peresepan (100\%) tidak memenuhi ketepan durasi penggunaan antibiotika.

\section{DAFTAR PUSTAKA}

Anderson, dkk., 2001, Handbook of Clinical Drug Data, $9^{\text {th }}$ ed., Stamford Connecticut.

Anonim, 1982, Sistem Kesehatan Nasional 6, Departemen Kesehatan Republik Indonesia, Jakarta.

Anonim, 1985, Buku Paket Prosedur Pelayanan di Puskesmas Bagi Pekarya Kesehatan Puskesmas, Departemen Kesehatan Republik Indonesia, Jakarta

Anonim, 1991a, Pedoman Perencanaan dan Pengelolaan Obat, Direktorat Jenderal Pengawasan Obat dan Makanan, Departemen Kesehatan Republik Indonesia, Jakarta 
Anonim, 1991b, Pedoman Kerja Puskesmas, Departemen Kesehatan Republik Indonesia, Jakarta.

Anonim, 1998, Meningkatkan Penelitian dan Pengembangan Kesehatan untuk Terapi Menunjang Pembangunan Nasional, Buku II, Departemen Kesehatan Republik Indonesia, Jakarta.

Anonim, 2000, Informatorium Obat Nasional Indonesia, Direktorat Jenderal POM, Departemen Kesehatan RI, Jakarta

Anonim, 2000, Informatorium Pengobatan Dasar di Puskesmas Berdasarkan Gejala, Depkes RI, Jakarta

Anonim, 2002, British National Formulatory 44, Royal Pharamceutical Society of Great Britain

Anonim,2011, http://www.jogjakota.go.id, di akses tanggal 12 april 2011

Anonim, $2011 b$, http://yogyakarta.bps.go.id/ di akses tanggal 4 mei 2011

Anonim, $2011 \mathrm{c}$

http://www.micromedex.com. DrugDex, Healthcare series Diakses 12 april 2011

Dipiro, J.T., Robert, A.B., Jane, M.P., William, J.S., 1996, Concepts in CLINICAL Pharmacokinetics, Second Edition, American Society of Health-System Pharmacist

Djaya, S, dkk, Pola penyakit penyebab kematian di perkotaan dan pedesaan di Indonesia, Studi Mortalitas Survei Kesehatan
Rumah Tangga (SKRT) 2001, J Kedokter Trisakti, , Vol.22 No.2 Mei-Agustus 2003

Dwiprahasto, I., 1995, Masalah Penggunaan Antibiotika, Dalam I., Dwiprahasto, E., Kristin, Mustofa (eds) : Penggunaan Antibiotika Rasional, Laboratorium Farmakologi Universitas Gadjah Mada, Yogyakarta

Foye, O.W., 1995, Prinsip-prinsip Kimia Medisinal, Jilid II, Edisi Kedua, Gadjah Mada University Press, Yogyakarta

Gan, V.H.S., 1980, Antimikroba : Pengantar. Dalam S. Gan, B. Suharto, V. Syamsudin, R. Setiabudy, A. Setiawai, V.H.S., Gan (eds) : Farmakologi dan Terapi, Bagian Farmakologi, Fakultas Kedokteran Universitas Indonesia, Jakarta

Hariani, H., 2006, Uji sensitifitas isolate Staphylococcus aureus dari usapan faring Penderita ISPA di RSU PKU Muhammadiyah Yogyakarta terhadap Antibiotika Golongan $\beta$ laktam, skripsi, Fakultas Farmasi Universitas Ahmad Dahlan Yogyakarta

Katzung, B.G., Editor, 1998, Basic and Clinical Pharmacology, $7^{\text {th }}$ ed., Appleton \& Lange, Connecticut

Santoso, B., 1990, Peta Klasifikasi Antibiotika dan Prinsip Pemilihan dan Pemakaiannya dalam Klinik. Dalam : S. Suryawati, E. Kristin, Mustofa, B. Santoso (eds) : Pemilihan dan Pemakaian Antibiotika dalam Klinik, Laboratorium Farmakologi 
Klinik, Fakultas Kedokteran Universitas Gadjah Mada, Yogyakarta

Setiabudy, R., 1995, Antimikrobai, dalam Ganiswara, (Ed), Farmakologi dan Terapi, Edisi IV, Bagian Farmakologi Fakultas Kedokteran Indonesia, Jakarta

Shagel, L., Yu, B.C., Andrew, 1988, Biofarmasetika dan Farmakoterapetika Terapan, diterjemahkan oleh Fasich, Syumsiah, S., Airlanga University Press, Surabaya

Soekardjo, B., Hardjono, S., Sondakh, R., 2003, Kimia Medisinal, Edisi 2, Airlangga University Press, Surabaya

Suwandi, U., , Mekanisme Kerja Antibiotika, Cermin Dunia Kedokteran, No. 76. 1992

Suryatenggara, Wibowo, dkk., 1990, Spektrum Kuman Infeksi Saluran
Pernafasan Bagian Bawah Serta Pola Kepekaannya, Dalam : S. Suryawati, E., Kristin, Mustofa, B. Santoso (eds) : Pemilihan dan Pemakaian Antibiotika dalam Klinik, Laboratorium Farmakologi Klinik, Fakultas Kedokteran Universitas Gadjah Mada, Yogyakarta

Whelan, A., dan Woodley, 1995, Pedoman Pengobatan dari Manual of Medical Therapeutics Department of Medicine Washington University, 27 edition, Yayasan Essentia Medica dan Andi Offset, Yogyakarta

Wattimena, J.R., 1991, Farmakologi dan Terapi Antibiotik, Fakultas Matematika dan Ilmu Pengetahuan Alam Institut Teknologi Bandung, Gadjah Mada University Press, Yogyakarta 